\title{
A Neural Network Decision Support System for Analysing Markets
}

\author{
Hamed Fazlollahtabar ${ }^{1, *}$ and Maryam Mohseninejad ${ }^{2}$
}

\author{
${ }^{1}$ Faculty of Management and Technology, Mazandaran University of Science and Technology, Tabarsi Street, \\ P.O. Box 734, Babol, Iran \\ ${ }^{2}$ Department of Industrial Engineering, Mazandaran University of Science and Technology, Tabarsi Street, \\ P.O. Box 734, Babol, Iran
}

\begin{abstract}
Today, markets are equipped with IT-based systems to facilitate the flow of information within markets and to provide useful information for producers and costumers. Therefore, real time decision making is a significant issue of IT environment for obtaining maximum profit in markets. A valuable tool for real time decision making are Decision Support Systems (DSSs). Here, we propose a DSS to identify a set of optimal markets for a producer. The producer aims to determine the markets that provide more profit for him via information systems of markets that analyze all transactions and prepare reports. Due to these reports the producer would decide about markets that provide the maximum profit. The effectiveness of the proposed integrated model is illustrated through numerical example.
\end{abstract}

Keywords: Information Technology (IT), Decision Support Systems (DSS), Markets.

\section{INTRODUCTION}

Information Technology (IT) is a general term that describes any technology that helps to produce, manipulate, store, communicate, and/or disseminate information [1, 2]. Making decisions concerning complicated systems (e.g., the management of operations, industrial processes, or investment portfolios) often requires our cognitive capabilities. Even though individual interactions among a system's variables may be well understood, predicting how the system will react to an external agent such as a strategy decision is often difficult [3]. Factors such as additional wages, machine breakdown, maintenance breaks, raw material usage, supply logistics, and future demand also need to be considered, however, because they will all affect the total financial outcome of this decision [4]. Many variables are involved in complex and often subtle interdependencies, and predicting the total outcome may be daunting [5].

As a matter of fact, human intuitive judgment and decision making can be far from optimal, and it worsens with complexity and stress. In many situations, the quality of decisions is important; therefore, aiding the deficiencies of human judgment and decision making has been a major focus of science throughout history. Disciplines such as statistics, economics, and operations research developed different approaches for making rational choices [6]. More recently, these methods, often enhanced by various techniques ensued from information science, cognitive psychology,

*Address correspondence to this author at the Faculty of Management and Technology, Mazandaran University of Science and Technology, Tabarsi Street, P.O. Box 734, Babol, Iran; Tel: +981132466177;

Fax: +981132190118; E-mail: hfazl@iust.ac.ir and artificial intelligence, have been implemented in the form of computer programs, either as stand-alone tools or as integrated computing environments for complex decision making. Such environments are often entitled as decision support systems (DSSs) [7, 8]. The concept of DSS is extremely broad, and its definitions vary, depending on the author's point of view. To consider all of the existing types of DSSs, we define them roughly as interactive computer-based systems that aid users in judgment and choice activities. Another name sometimes used as a synonym for DSS is knowledge-based systems, which refers to their attempt to formalize domain knowledge so that it is amenable to mechanized reasoning [9]. Decision support systems can help human cognitive deficiencies by integrating various sources of information, providing intelligent access to required knowledge, and aiding the process of structuring decisions [10]. They can also support choice among well-defined alternatives and build on formal approaches, such as the methods of engineering economics, operations research, statistics, and decision theory [11]. They can also employ artificial intelligence methods to heuristically address problems that are intractable by common techniques. Proper application of decision-making tools increases productivity, efficiency, and effectiveness, and gives many businesses a comparative advantage over their competitors, allowing them to make optimal choices for technological processes and their parameters, planning business operations, logistics, or investments.

The remainder of the work is as follows. Next, literature review is presented. In Section 3, the problem is described. Section 4 provides the proposed DSS structure and formulations. An illustrative example is given in Section 5. We conclude in Section 6. 


\section{LITERATURE REVIEW}

The new business environment is characterized by unpredictability, complexity, and changes [12]. This is especially the case with the development of new technologies and increasing competition on the Internet. Easier access to information for customers and the increasing dynamism of the environment have transformed the basis of competitiveness and have led to a revolution in marketing and management tools [13]. In order to deal with these new situations, one of the most critical elements for firms is the ability to set and manage pricing strategies, especially for companies active in highly dynamic and "hypercompetitive" industries [14].

The catalyst for entry success of the high-tech industry in emerging market has received attention in international business, where many researchers underline the critical role of firm competencies to enhance entry success. Further, existing studies have discussed the types of competencies needed but only in a limited scope. Subramaniam and Venkrataman [15] highlighted new product development (NPD) and innovation, others are exploring marketing $[16,17]$, or business networks [18-20]. Broader studies are simultaneously observing NPD and marketing [21-23], investigating business networks and product process innovation [24, 25], or exploring networking and marketing $[26,27]$. From these studies, we find that researchers concern with the roles of networking, NPD, and marketing, and also find that these competencies are indirectly related [28].

In the past decades there has been a growing interest in investigating the relation between a firm's market orientation and innovation [29]. Though a significant amount of research has revealed a positive relation between market orientation (MO) and firm performance [30], other research suggests that the effect of MO on performance is not direct, but instead is via innovation [30]. A review of the extant literature that examines the relation between $\mathrm{MO}$ and innovation also reveals a cultural bias towards more economically developed countries and Western individualistic cultures [31]. Grinstein's [32] meta-analysis, for example, suggests that more than $80 \%$ of the studies were based on samples from developed countries, mostly Western individualistic societies. Given that MO is regarded as a form of organizational culture, which is often shaped by national cultures, there is a need to integrate $\mathrm{MO}$ and innovation research with underlying cultural factors. Indeed, the theories about corporate culture and innovation that have evolved in the context of Western cultural values and institutions may not readily apply to other cultures. It is important to examine the relation between $\mathrm{MO}$ and innovation in non-Western settings.

\section{PROBLEM DESCRIPTION}

One of the most important issues of the firms produce multiple types of products (e.g., diary, agricultural, etc), is finding the target markets. Producers aim to find the markets maximizing their profit. In this work, we propose a decision support system regarding to producer behavior. A producer should choose the best set of markets amongst the existingones. The producer confronts with different markets in different geographical locations and with different environmental conditions. The decision here is to determine a set of products for each market maximizing the profit. Let's assume markets demand for a same group of products (for instance, diary) are listed in one stage. Thus, several stages are formed due to several product types.

In each stage, the producer chooses a market and after satisfying this market based on demand analysis, decides about the next market. The procedure continues till the last market. In each market, the producer sells a group of products, but not all kinds of products. Therefore, demands for some types of the products exist in one set of the markets and for other types of products in other sets of markets. The aim is to find the sets of the markets for each group of the products so that to maximize the profit of the producer.

To simplify the proposed problem, we consider a network in which markets are in stages. Each stage indicates the markets that demand for a same group of products. The aim of the producer is to supply a market that maximizes the profit. In each stage the procedure repeated till the last stage. Now, the query is how to choose a market in a stage with maximum profit. The tool which helps choosing the market with maximum profit is a decision support system (DSS). The proposed DSS, functions based on the producer behavior. Regarding to the information flow amongst markets, the DSS uses the information and analyzes them. For each market the DSS facilitates the decision making for the producer. The DSS computes the profit of the producer for each market in each stage. The computations are reported to the producer, and by the aid of the DSS, producer chooses the best market which maximizes his profit. The configuration of the proposed market network is presented in Figure 1. 


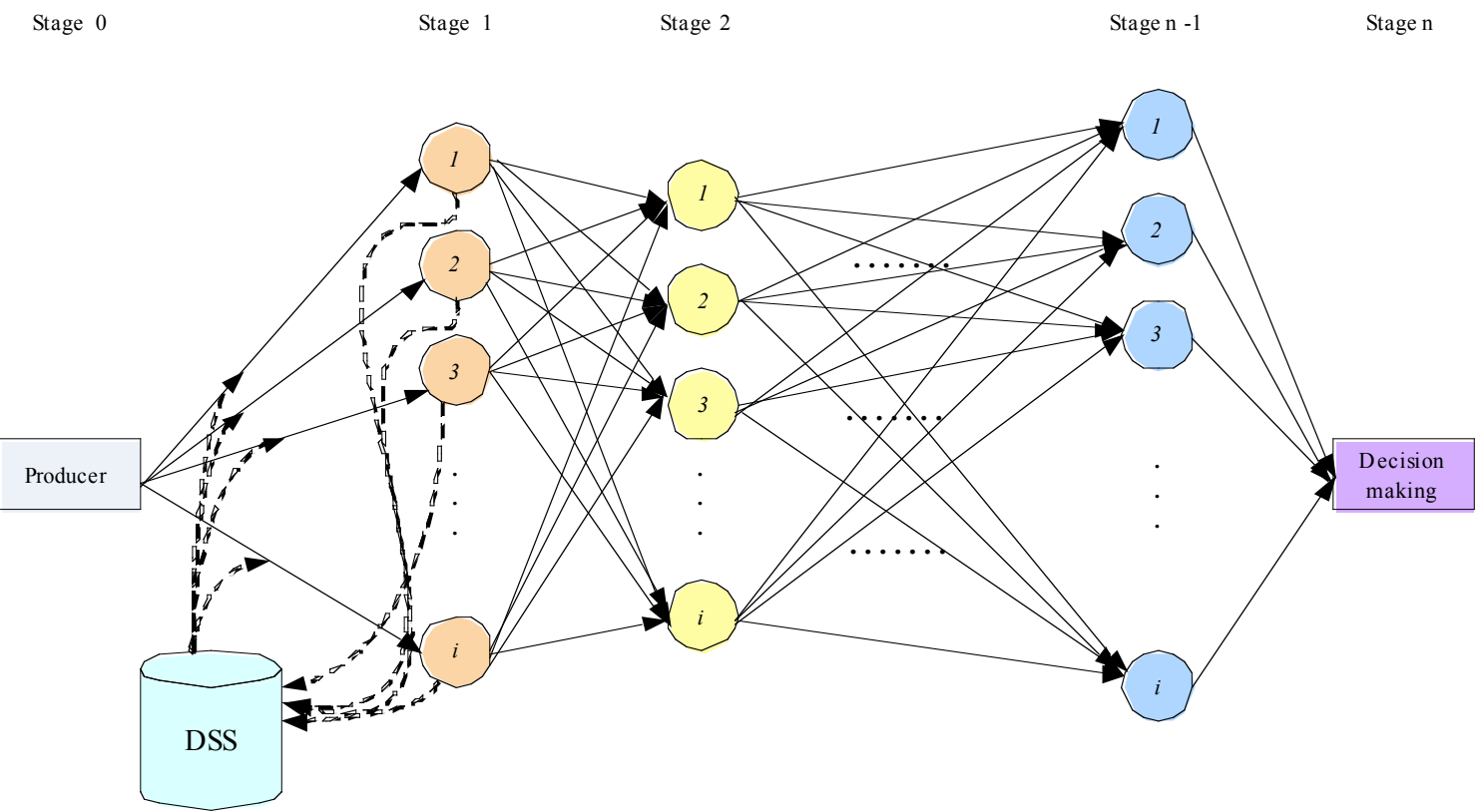

Figure 1: The configuration of the proposed market network.

The assumptions employed in our work are as follows:

- $\quad$ The markets can be differentiated

- $\quad$ The products can be divided into several sets

- Markets in a same stage demand for a same group of products

- Only profit maximization is considered as a decision for producers

In the next section, the structure of the proposed DSS is described with details.

\section{THE PROPOSED DSS}

As stated before, the DSS functions as a decision aid for the producer to find the markets maximizing his profit. The basis of the proposed DSS is producer behavior theory. Using the market information flow, a real time decision making in any instances takes place. In any markets, different information is reported due to fluctuations in supply and demand. The fluctuations affect the prices and the amount of products to be supplied. The aforementioned information is considered as input of the proposed DSS and after an analysis layer, the output will be the total expected profit. The analysis layer is based on profit maximization in producer behavior theory.

The analysis layer functions as an optimization tool in producer behavior theory. Obviously, profit is the difference between total revenue and total expenses.
The notations of profit maximization model are as follows:

$\begin{array}{cc}\text { Index: } & \\ j & \text { Counter for products; } j=1,2, \ldots, m \\ & \text { Parameters: } \\ p_{j} & \text { Price of product } j^{\text {th }} \\ q_{j} & \text { Quantity of product } j^{\text {th }} \\ r_{j} & \text { Cost for input } j^{\text {th }} \\ x_{j} & \text { Quantity of input } j^{\text {th }} \\ F & \text { Function }\end{array}$

The mathematical model for profit:

$\operatorname{Max} \pi=\sum_{j=1}^{m} p_{j} q_{j}-\sum_{i=1}^{m} r_{j} x_{j} \Rightarrow \pi=\sum_{i=1}^{m} p_{j} q_{j}-\sum_{j=1}^{m} r_{j} F\left(q_{1}, \ldots, q_{j}\right)$

where $x_{j} s$ are the function of the quantities of the outputs $F\left(q_{1}, \ldots, q_{j}\right)$. To solve the profit maximization problem of a producer who desires to maximize the profit from the above equation, we set the partial derivatives equal to zero (first order conditions):

$\frac{\partial \pi}{\partial q_{1}}=p_{1}-r_{1} f_{1}=0$

$\frac{\partial \pi}{\partial q_{2}}=p_{2}-r_{2} f_{2}=0$

$\frac{\partial \pi}{\partial q_{j}}=p_{j}-r_{j} f_{j}=0$

where $f_{j}$ is the Marginal Productivity (MP): 
$f_{j}=\frac{\partial x_{j}}{\partial q_{j}}$.

Moving the price terms to the right and dividing by marginal productivity, $r_{j}=\frac{p_{j}}{f_{j}}$, or substituting the MP formulae:

$r_{j}=p_{j} \frac{\partial q_{j}}{\partial x_{j}}$

The value of MP of $x_{j}$ for the production of each output must be equated to the price of $x_{j}$. The producer could increase the profit by increasing the employment of $x_{j}$ if its return in the production of any products exceeded its costs. For more in-depth analysis, we investigate second order conditions which require,

$\left|\begin{array}{cccc}-r_{1} f_{11} & -r_{1} f_{12} & \ldots & -r_{1} f_{1 j} \\ -r_{2} f_{21} & -r_{2} f_{22} & \ldots & -r_{2} f_{2 j} \\ & \ldots & \\ -r_{j} f_{j 1} & -r_{j} f_{j 2} & \ldots & -r_{j} f_{j j}\end{array}\right|>0$,

While $r_{j}$ is positive, the second order conditions imply that the marginal productivity of each output must be increasing. When both first and second order conditions are satisfied, the profit is maximized. As a result, the amounts of profits in any markets are gained. Now, we have to select the set of markets which provide more integrated profit.

As stated above, the fluctuations in supply and demand cause dynamic structure of prices. To consider these dynamisms, we apply artificial neural network [33]. A comprehensive description about neural networks and the applied approach is presented in next section.

\subsection{Artificial Neural Network}

An artificial neural network (ANN), usually called "neural network" (NN), is a mathematical model or computational model based on biological neural networks [34]. It consists of an interconnected group of artificial neurons and processes information using a connectionist approach to computation. In most cases an ANN is an adaptive system that changes its structure based on external or internal information that flows through the network during the learning phase. In more practical terms neural networks are non-linear statistical data modeling tools. They can be used to model complex relationships between inputs and outputs or to find patterns in data. One type of representation in neural network is component based representation. This kind of more general representation is used by some neural network software [35].

There is no precise agreed-upon definition among researchers as to what a neural network is, but most would agree that it involves a network of simple processing elements (neurons), which can exhibit complex global behavior, determined by the connections between the processing elements and element parameters [36]. The original inspiration for the technique was from examination of the central nervous system and the neurons (and their axons, dendrites and synapses) which constitute one of its most significant information processing elements. In a neural network model, simple nodes (called variously "neurons", "neurodes", "PEs" ("processing elements") or "units") are connected together to configure a network of nodes - hence the term "neural network". While a neural network does not have to be adaptive, its practical use comes with algorithms designed to alter the strength (weights) of the connections in the network to produce a desired signal flow [37].

Neural network models in artificial intelligence are usually referred to as artificial neural networks (ANNs); these are essentially simple mathematical models defining a function, $f: X \rightarrow Y$. Each type of ANN model corresponds to a class of such functions.

The word network in the term 'artificial neural network' arises because the function $f(x)$ is defined as a composition of other functions $g_{i}(x)$, which can further be defined as a composition of other functions. This can be conveniently represented as a network structure, with arrows depicting the dependencies between variables. A widely used type of composition is the nonlinear weighted sum, where $f(x)=K\left(\sum_{i} w_{i} g_{i}(x)\right)$, where $K$ is some predefined function, such as the hyperbolic tangent. It will be convenient for the following to refer to a collection of functions $g_{\mathrm{i}}$ as simply a vector $g=\left(g_{1}, g_{2}, \ldots, g_{n}\right)$. Considering the multi layer organization of our data that are the prices, we apply a multilayer perceptron neural network.

\subsubsection{Multilayer Perceptron}

A multilayer perceptron is a feed forward artificial neural network model that maps sets of input data onto a set of appropriate output. It is a modification of the standard linear perceptron in that it uses three or more layers of neurons (nodes) with nonlinear activation 
functions, and is more powerful than the perceptron in that it can distinguish data that is not linearly separable, or separable by a hyperplane. If a multilayer perceptron consists of a linear activation function in all neurons, that is, a simple on-off mechanism to determine whether or not a neuron fires, then it is easily proved with linear algebra that any number of layers can be reduced to the standard two-layer input-output model. What makes a multilayer perceptron different is that each neuron uses a nonlinear activation function which was developed to model the frequency of action potentials, or firing, of biological neurons in the brain. This function is modeled in several ways, but must always be normalizable and differentiable. The multilayer perceptron consists of an input and an output layer with one or more hidden layers of nonlinearlyactivating nodes. Each node in one layer connects with a certain weight $w_{i j}$ to every other node in the following layer. Learning occurs in the perceptron by changing connection weights (or synaptic weights) after each piece of data is processed, based on the amount of error in the output compared to the expected result. This is an example of supervised learning, and is carried out through back propagation, a generalization of the least mean squares algorithm in the linear perceptron.

The inputs of the MLP are the prices of previous periods and the outputs are again the prices of the products. The difference between these two types of prices is:

the input is the price based on which the producer set an amount of the products to send to the markets; but the output are the prices that the producer obtains for his products, i.e. during the process of analyzing the prices in markets and deciding to send the products ensue a change in prices in dynamic markets. After a training period, the required equations for future applications are achieved. Hence, the proposed MLP helps to consider fluctuations in prices and also it is a useful approach for this concept.

\section{ILLUSTRATIVE EXAMPLE}

To illustrate the validity of the proposed model, an example is presented. We consider three products and three markets in stages one, two, and three. The configuration of the proposed example is shown in Figure 2.

The production functions for products $(1,2,3)$ are as follows:

$$
\begin{aligned}
& x_{1}=q_{1} q_{2}+q_{3}, \\
& x_{2}=2 q_{1}-q_{2}+q_{3}, \\
& x_{3}=q_{1}^{2}+q_{2} q_{3} .
\end{aligned}
$$

Note that these production functions are obtained using the ratio of materials composing a product. To clarify these production functions, consider three products of cheese, butter, and yoghurt. The basic material for all these products is milk but some other additives are also included (in the equations assume $q_{1}, q_{2}$, and $q_{3}$ ) with different ratios. Therefore, the production functions for them are different. To facilitate the computations MATLAB 7.0 package is applied. Also NN Tool Box is applied for multilayer perceptron section. The input and output of the prices and costs for the three markets in the first stage are given below, i.e., the first three rows are for prices and the second three rows are for costs.

$$
\text { Input }=\left[\begin{array}{ll}
36 & 45543623543639 ; \ldots
\end{array}\right.
$$

45423330333936 48; ...

$5451394245573642 ; \ldots$

$0911151007151109 ; \ldots$

$1112090709111013 ; \ldots$

$1315111212160911]$

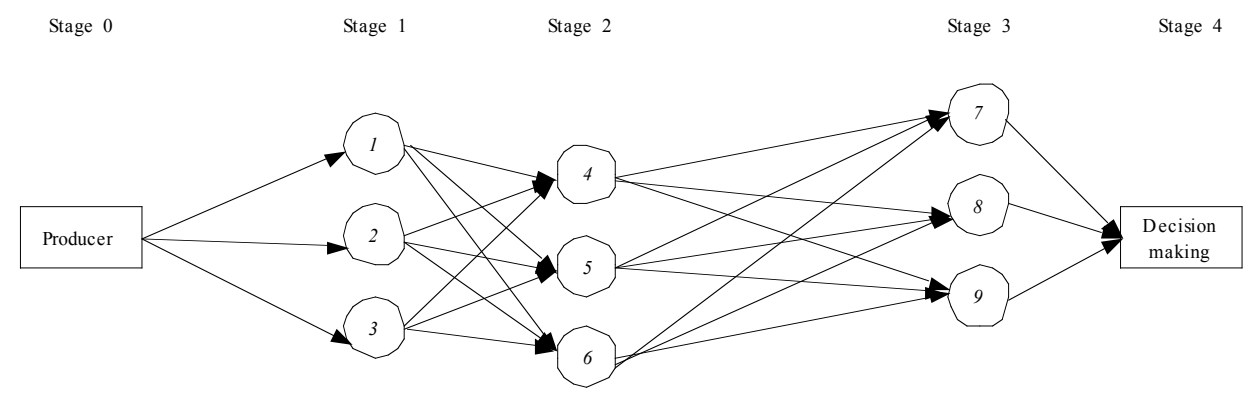

Figure 2: The configuration of the proposed example. 
output $=[39.053 .452 .836 .930 .051 .045 .040 .5 ; \ldots$

$42.042 .934 .529 .133 .642 .039 .050 .4 ; \ldots$

$55.549 .540 .543 .543 .852 .537 .545 .0 ; \ldots$

$9.8010 .516 .010 .98 .0015 .512 .09 .00 ; \ldots$

$10.012 .010 .08 .009 .8011 .811 .013 .2 ; \ldots$

$13.814 .312 .012 .812 .015 .59 .9011 .5] ;$

The inputs are inserted into MATLAB 7.0 user interface and the required settings are performed. Consequently the outputs are extracted. MATLAB 7.0 user interface is shown in Figure 3.

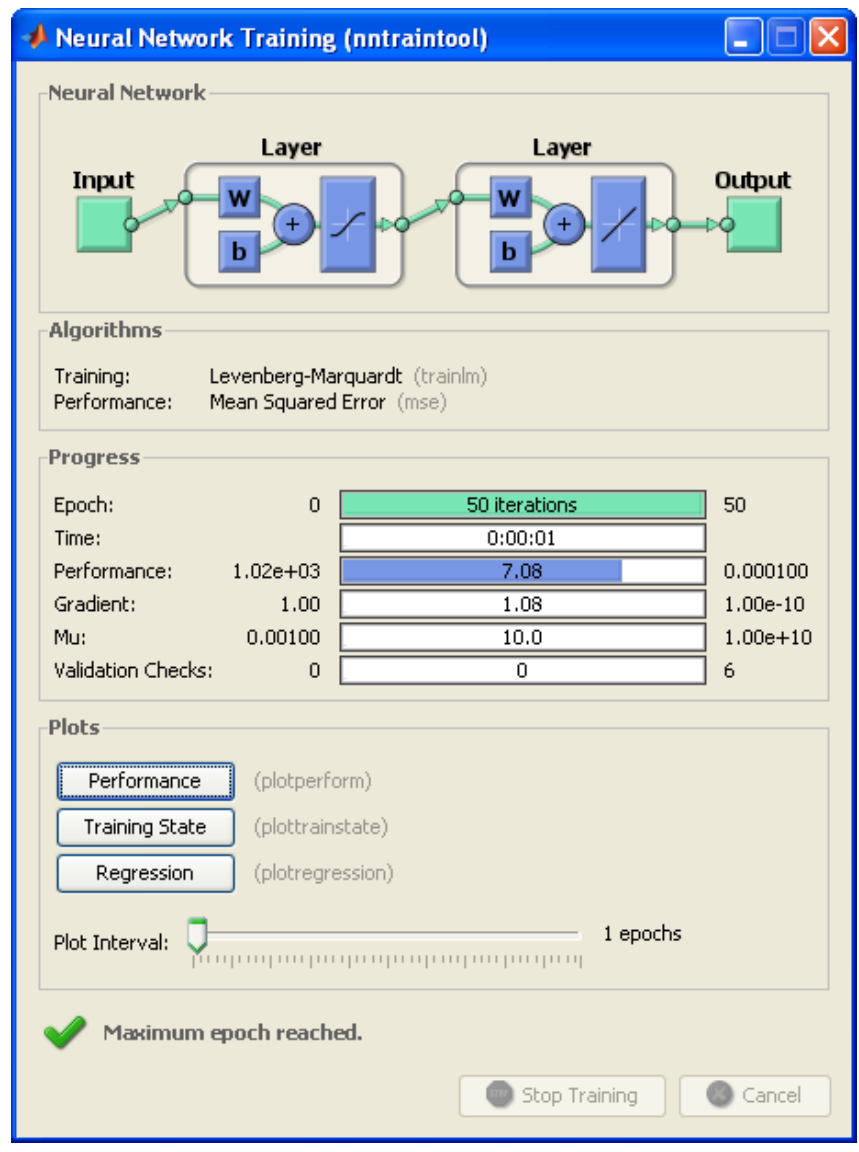

Figure 3: MATLAB user interface.
Using the outputs the optimization is worked out (first order condition) and the following results are obtained for the quantity of products leading to achieve the profit of each market in the first stage. The results are given in Table 1.

$$
\begin{aligned}
& \pi=p_{1} q_{1}+p_{2} q_{2}+p_{3} q_{3}-r_{1}\left(q_{1} q_{2}+q_{3}\right) \\
& \left.+r_{2}\left(2 q_{1}-q_{2}+q_{3}\right)+r_{3}\left(q_{1}^{2}+q_{2} q_{3}\right)\right)
\end{aligned},
$$

The computations are repeated for the markets in the second and the third stages. We consider the computation for the status that we move from a market in the previous stage to another market in the next stage.

The results for stages two and three are given in Tables 2 and $\mathbf{3}$, respectively. These results are obtained for the quantity of products resulting to gain the profit of each market in the second and the third stages.

Thus, the need for using a DSS based on MLP is now proved. But the application is limited to the existence of data for prices since the MLP method employs fluctuation of supply and demand during a specified period which is more reasonable in economical view point.

\section{CONCLUSIONS}

We proposed a decision support system as a tool to help producers for determining a set of markets providing maximum integrated profit. The producer would estimate the prices and costs using the information received from any markets. To control the dynamism of prices and costs, a multilayer perceptron in neural network was applied. The applicability and effectiveness of the proposed model was illustrated in an example and fully justified in a discussion. The contributions were the use of MLP as computational core of a DSS for costs and benefits data, employing production function for analyzing producer behavior.

Table 1: The Products Quantities for Stage One

\begin{tabular}{|c|c|c|c|}
\hline $\begin{array}{c}\text { Markets } \\
\text { Product quantity }\end{array}$ & Market one & Market two & Market three \\
\hline \hline$q_{1}$ & 0.3 & 0.2 & 0.6 \\
\hline$q_{2}$ & 0.6 & 1.7 & 3.4 \\
\hline$q_{3}$ & 5.9 & 95.226 & 72.8 \\
\hline$\pi$ & 67.902 & & 72.6 \\
\hline
\end{tabular}


Table 2: The Products Quantities for Stage Two

\begin{tabular}{|c|c|c|c|}
\hline $\begin{array}{l}\text { Markets } \\
\text { Product quantity }\end{array}$ & From market one to four & From market one to five & From market one to six \\
\hline$q_{1}$ & 0.2 & 0.1 & 0.2 \\
\hline$q_{2}$ & 0.4 & 2.1 & 0.5 \\
\hline$q_{3}$ & 6.3 & 5.3 & 6.4 \\
\hline$\pi$ & 48.352 & 131.059 & 49.654 \\
\hline $\begin{array}{l}\text { Markets } \\
\text { Product quantity }\end{array}$ & From market two to four & From market two to five & From market two to six \\
\hline$q_{1}$ & 0.2 & 0.3 & 0.5 \\
\hline$q_{2}$ & 0.4 & 0.8 & 0.2 \\
\hline$q_{3}$ & 6.3 & 5.8 & 9.3 \\
\hline$\pi$ & 47.742 & 61.866 & 29.882 \\
\hline $\begin{array}{l}\text { Markets } \\
\text { Product quantity }\end{array}$ & From market three to four & From market three to five & From market three to six \\
\hline$q_{1}$ & 0.2 & 0.1 & 0.1 \\
\hline$q_{2}$ & 0.5 & 1.1 & 1.1 \\
\hline$q_{3}$ & 6.1 & 6.4 & 6.4 \\
\hline$\pi$ & 45.059 & 78.177 & 78.177 \\
\hline
\end{tabular}

Table 3: The Products Quantities for Stage Three

\begin{tabular}{|c|c|c|c|}
\hline $\begin{array}{c}\text { Markets } \\
\text { Product quantity }\end{array}$ & From market four to seven & From market four to eight & From market four to nine \\
\hline$q_{1}$ & 0.4 & 0 & 0.2 \\
\hline$q_{2}$ & 0.2 & 2.1 & 1.5 \\
\hline$q_{3}$ & 3.7 & 3.4 & 3.4 \\
\hline$\pi$ & 61.618 & 115.302 & 76.852 \\
\hline $\begin{array}{c}\text { Markets } \\
\text { Product quantity }\end{array}$ & From market five to seven & From market five to eight & From market five to nine \\
\hline$q_{1}$ & 0.2 & 0 & 0 \\
\hline$q_{2}$ & 1.7 & 1.9 & 1.6 \\
\hline$q_{3}$ & 3.9 & 3.4 & 4.4 \\
\hline$\pi$ & 94.872 & 92.072 & 71.192 \\
\hline $\begin{array}{c}\text { Markets } \\
\text { Product quantity }\end{array}$ & From market six to seven & From market six to eight & From market six to nine \\
\hline$q_{1}$ & 0 & 0.1 & 0.1 \\
\hline$q_{2}$ & 2.2 & 1 & 1.7 \\
\hline$q_{3}$ & 3.9 & 3.3 & 3.5 \\
\hline$\pi$ & 138.974 & 38.876 & 92.793 \\
\hline
\end{tabular}

Managers can make use of the proposed methodology to obtain optimal markets for investment purpose. For future research considering a genetic algorithm for optimization of extensive markets with large amount of data is suggested. 


\section{REFERENCES}

[1] Hassanlou K, Fathian M, Akhavan P, Azari A. Information technology policy trends in the world. Technology in Society 2009; 31(2): 125-132.

http://dx.doi.org/10.1016/j.techsoc.2009.03.005

[2] Arvanitis S, Loukis EN. Information and communication technologies, human capital, workplace organization and labour productivity: A comparative study based on firm-level data for Greece and Switzerland. Information Economics and Policy $2009 ; 21(1):$ 43-61. http://dx.doi.org/10.1016/j.infoecopol.2008.09.002

[3] Bekaerta G, Harvey CR. Research in emerging markets finance: looking to the future. Emerging Markets Review 2002; 3(4): 429-448.

http://dx.doi.org/10.1016/S1566-0141(02)00045-6

[4] Viswanathan S, Wang JJD. Market architecture: limit-order books versus dealership markets. Journal of Financial Markets 2002; 5(2): 127-167.

http://dx.doi.org/10.1016/S1386-4181(01)00025-8

[5] Theissen E. Market structure, informational efficiency and liquidity: An experimental comparison of auction and dealer markets. Journal of Financial Markets 2000; 3(4): 333-363. http://dx.doi.org/10.1016/S1386-4181(00)00010-0

[6] Srinivasan V, Kim YH. Decision support for integrated cash management. Decision Support Systems 1986; 2(4): 347363.

http://dx.doi.org/10.1016/0167-9236(86)90005-9

[7] Dewan RM, Hansen SC. The role of user capability and incentives in group and individual decision support systems: An economics perspective. Decision Support Systems 1994; 12(1): $25-40$.

http://dx.doi.org/10.1016/0167-9236(94)90072-8

[8] Chang C-W, Chiang D, Chang Y-C, Hu N-Z. Critical equipments decision support system for process layout environment: a case of wafer FAB. International Journal of Industrial Engineering: Theory. Applications and Practice 2010; 17(3): 30-40.

[9] Bhargava HK, Power DJ, Sun D. Progress in Web-based decision support technologies. Decision Support Systems 2007; 43(4): 1083-1095.

http://dx.doi.org/10.1016/j.dss.2005.07.002

[10] Wong J-T, Chen K-H, Su C-T. Replenishment decision support system based on modified particle swarm optimization in a VMI supply chain. International Journal of Industrial Engineering: Theory. Applications and Practice 2009; 16(1): 1-12.

[11] Fazlollahi B, Parikh MA, Verma S. Adaptive decision support system. Decision Support Systems 1997; 20(4): 297-315. http://dx.doi.org/10.1016/S0167-9236(97)00014-6

[12] Garrigós F, Palacios D, Narangajavana Y. Improving the perceptions of hotel managers. Annals of Tourism Research 2008; 35(2): 359e380.

[13] Jallat F, Ancarani F. Yield management, dynamic pricing and CRM in telecommunications. Journal of Services Marketing 2008; 22(6): 465e478.

http://dx.doi.org/10.1108/08876040810901882

[14] Narangajavana Y, Garrigos-Simon FJ, García JS, ForgasColl S. Prices, prices and prices: A study in the airline sector. Tourism Management 2014; 41: 28-42. http://dx.doi.org/10.1016/j.tourman.2013.08.008

[15] Subramaniam $M$, Venkrataman $N$. Determinants of transnational new product development capability: Testing the influence of transferring and deploying tacit overseas knowledge. Strategic Management Journal 2001; 22: 359378. http://dx.doi.org/10.1002/smj.163

[16] Salomo S, Brickmann J, Talke K. Functional management competence and growth of young technology-based firms.
Creativity and Innovation Management 2008; 17(3): 186-203. http://dx.doi.org/10.1111/j.1467-8691.2008.00485.x

[17] Vorhies DW, Morgan RE, Autry CW. Product-market strategy and the marketing capabilities of the firm: Impact on market effectiveness and cash flow performance. Strategic Management Journal 2009; 30: 1310-1334. http://dx.doi.org/10.1002/smj.798

[18] Lee GK. The significance of network resources in the race to enter emerging product markets: The convergence of telephony communications and computer networking, 19892001. Strategic Management Journal 2007; 28(1): 17-37. http://dx.doi.org/10.1002/smj.566

[19] Li JJ. The formation of managerial networks of foreign firms in China: The effects of strategic orientations. Asia Pacific Journal of Management 2005; 22(4): 423-443. http://dx.doi.org/10.1007/s10490-005-4118-8

[20] Nielsen C. The global chess game... or is it to go? Market entry strategies for emerging market. Thunderbird International Business Review 2005; 47(4): 397-427. http://dx.doi.org/10.1002/tie.20060

[21] Aydin S, Cetin AT, Ozer G. The relationship between marketing and product new development process and their effects on firm performance. Academy of Marketing Studies Journal 2007; 11(1): 53-68.

[22] Bruni DS, Verona G. Dynamic marketing capabilities in science-based firms: An exploratory investigation of the pharmaceutical industry. British Journal of Management 2009; 20: S101-S117.

http://dx.doi.org/10.1111/j.1467-8551.2008.00615.x

[23] Song M, Droge C, Hanvanich S, Calantone R. Marketing and technology resource complementarity: An analysis of their interaction effect in two environmental contexts. Strategic Management Journal 2005; 26(3): 259-276.

http://dx.doi.org/10.1002/smj.450

[24] Pittaway L, Robertson M, Munir K, Denyer D, Neely A. Networking and innovation: A systematic review of the evidence. International Journal of Management Reviews 2004; 5/6(3/4): 137-168.

http://dx.doi.org/10.1111/j.1460-8545.2004.00101.x

[25] Ritter T, Gemunden HG. Network competence: Its impact on innovation success and its antecedents. Journal of Business Research 2003; 56: 745-755. http://dx.doi.org/10.1016/S0148-2963(01)00259-4

[26] Fan Y. Guanxi, government and corporate reputation in China - Lessons for international companies. Marketing Intelligence and Planning 2007; 25(5): 499-510. http://dx.doi.org/10.1108/02634500710774969

[27] Yu J, Gilbert BA, Oviatt BM. Effects of alliances, time, and network cohesion on the initiation of foreign sales by new ventures. Strategic Management Journal 2011; 32: 424-446. http://dx.doi.org/10.1002/smj.884

[28] Wang K-J, Lestari YD. Firm competencies on market entry success: Evidence from a high-tech industry in an emerging market. Journal of Business Research 2013; 66: 2444-2450. http://dx.doi.org/10.1016/j.jbusres.2013.05.033

[29] Lukas BA, Ferrell OC. The effect of market orientation on product innovation. Journal of the Academy of Marketing Science 2000; 28: 239-247. http://dx.doi.org/10.1177/0092070300282005

[30] Wang CL, Chung HFL. The moderating role of managerial ties in market orientation and innovation: An Asian perspective. Journal of Business Research 2013; 66: 24312437. http://dx.doi.org/10.1016/j.jbusres.2013.05.031

[31] Ellis P. Market orientation and performance: A meta-analysis and cross-national comparisons. Journal of Management Studies 2006; 43: 1089-1107.

http://dx.doi.org/10.1111/j.1467-6486.2006.00630.x 
[32] Grinstein A. The effect of market orientation and its components on innovation consequences: A meta-analysis. Journal of the Academy of Marketing Science 2008; 36: 166173.

http://dx.doi.org/10.1007/s11747-007-0053-1

[33] Syriopoulos T, Roumpis E. Dynamic correlations and volatility effects in the Balkan equity markets, Journal of International Financial Markets. Institutions and Money 2009; 19(4): 565-587.

http://dx.doi.org/10.1016/j.intfin.2008.08.002

[34] Haykin S. Neural Networks: A Comprehensive Foundation (2 ed.). Prentice Hall 1998; ISBN 0132733501.
[35] Castellani M, Rowlands H. Evolutionary Artificial Neural Network Design and Training for wood veneer classification. Engineering Applications of Artificial Intelligence 2009; 22(4-5): 732-741.

http://dx.doi.org/10.1016/j.engappai.2009.01.013

[36] Ban JC, Chang CH, Lin SS, Lin YH. Spatial complexity in multi-layer cellular neural networks. Journal of Differential Equations 2009; 246(2): 552-580.

[37] Gabrijel I, Dobnikar A. On-line identification and reconstruction of finite automata with generalized recurrent neural networks. Neural Networks 2003; 16(1): 101-120. http://dx.doi.org/10.1016/S0893-6080(02)00221-6

Received on 15-05-2015

Accepted on 25-06-2015

Published on 30-07-2015

(C) 2015 Fazlollahtabar and Mohseninejad; Licensee Lifescience Global.

This is an open access article licensed under the terms of the Creative Commons Attribution Non-Commercial License (http://creativecommons.org/licenses/by-nc/3.0/) which permits unrestricted, non-commercial use, distribution and reproduction in any medium, provided the work is properly cited. 